\begin{tabular}{l|l|l|l} 
Case Reports in & Case Rep 0phthalmol 2010;1:24-29 & Published online: July 2, 2010 & $\begin{array}{l}\text { @ 2010 S. Karger AG, Basel } \\
\text { ISSN 1663-2699 } \\
\text { www.karger.com/cop }\end{array}$ \\
\hline
\end{tabular}

\title{
Bilateral Keratectasia 34 Years after Corneal Transplant
}

\author{
Xavier Valldeperas ${ }^{a, b}$ Martina Angi $\mathrm{j}^{\mathrm{b}, \mathrm{c}}$ Vito Romano ${ }^{\mathrm{d}}$ \\ Mario R. Romano ${ }^{\text {b, e }}$ \\ aDepartment of Ophthalmology, Hospital Universitari Germans Trias i Pujol, \\ Badalona, Spain; 'St Paul's Eye Unit, Royal Liverpool University Hospital, \\ Liverpool, UK; 'Department of Ophthalmology, Campus Biomedico University, \\ Rome, dDepartment of Ophthalmology, S. Sebastiano Hospital, Caserta, and \\ eDepartment of Ophthalmology, Istituto Clinico Humanitas, Rozzano, Italy
}

\section{Key Words}

Bilateral keratectasia $\cdot$ Penetrating keratoplasty $\cdot$ Bilateral keratoconus

\begin{abstract}
We report the clinical findings of a patient with severe bilateral keratectasia 34 years after a penetrating keratoplasty (PK) in both eyes. An otherwise healthy 67-year-old man complained of deterioration of the eyesight in both eyes over the last 6 months. The patient was diagnosed with bilateral keratoconus at the age of 32 years, and he underwent a bilateral PK. At presentation, visual acuity was 20/200 in the right eye and light perception in the left eye. A Pentacam pachymetric map revealed a central pachymetry of $720 \mu \mathrm{m}$ in the right eye and of $710 \mu \mathrm{m}$ in the left eye, as well as an average paracentral pachymetry of 436 and $270 \mu \mathrm{m}$ in the $9-\mathrm{mm}$ zone in the right and the left eye, respectively. Corneal topography revealed bilateral irregular and asymmetric bowing with generalized steepening and high corneal power. We describe a case of bilateral keratectasia 34 years after PK in a patient who was originally diagnosed with bilateral keratoconus.
\end{abstract}

\section{Introduction}

Keratoglobus is a non-progressive or minimally progressive, non-inflammatory corneal degeneration defined by a globular protrusion of the cornea with or without enlargement of the corneal diameter and a generalized thinning mainly in the periphery, without the presence of neovascularization [1]. The cornea is usually transparent, but acute corneal edema due to rupture of Descemet's membrane and perforation, even from minimal trauma, is the most frequent complication [2]. This rare condition is usually bilateral and has been associated with several eye conditions, such as blue sclera syndrome [3], Leber's congenital amaurosis [4], pellucid marginal degeneration [5], inflammatory 
orbital pseudotumor, chronic marginal blepharitis, and chronic eye rubbing, and it can also develop following penetrating keratoplasty (PK) [1]. In addition, it has been related to joint hypermobility and consanguineous parents [6]. Acquired keratoglobus has also been described in association with vernal keratoconjunctivitis [1], hyperthyroidism [7], advanced keratopathy (keratoconus), trauma and exophthalmos [8]. The pathogenesis and the molecular events responsible for the disease expression remain unclear [3], and there are limited reports of the genetic background of keratoglobus [4].

\section{Case Report}

An otherwise healthy 67-year-old man presented with progressive deterioration of vision in both eyes over the last 6 months. Best-corrected visual acuity (BCVA), using contact lens combined with spectacle correction, was $20 / 200$ in the right eye (-18.50 dpt sph, $-1.50 \mathrm{dpt}$ cyl) and light perception $(-4.00 \mathrm{dpt}$ sph) in the left eye.

The patient was diagnosed with bilateral keratoconus at the age of 32 years, with no associated connective tissue disorders or other systemic diseases. At that time, BCVA was 20/200 in the right eye and 20/70 in the left eye, and refraction was $-14.00 \mathrm{dpt}$ in both eyes. One year after the keratoconus diagnosis, the patient underwent a $\mathrm{PK}$ in the left eye for a progressive deterioration of the eyesight and thinning of the cornea. Six years later, another PK was performed in the right eye.

A 6.5-mm diameter keratoplasty was performed in the right eye and a 7.00-mm diameter keratoplasty in the left eye to include the abnormal cornea. BCVA recovered rapidly to 20/40 in the left eye and 20/50 in the right eye after the surgeries, and it remained stable until six months before the patient attended our clinic.

At presentation, slit-lamp examination showed clear corneal buttons (fig. 1), globular protrusion of the cornea with ectatic profile and midperipheral thinning (fig. 2). Bilateral full-thickness corneal scars, resulting from the previous $\mathrm{PK}$, were also noted. Vertical and horizontal corneal diameters were 11.0 and $11.6 \mathrm{~mm}$, respectively, in the right eye, and 11.0 and $11.8 \mathrm{~mm}$, respectively, in the left eye. Intraocular pressure (IOP) was $12 \mathrm{~mm} \mathrm{Hg}$ in the right eye and $14 \mathrm{~mm} \mathrm{Hg}$ in the left eye. Anterior chamber depth was $4.63 \mathrm{~mm}$ in the right eye and $5.71 \mathrm{~mm}$ in the left eye, and axial length was 33.04 and $35.40 \mathrm{~mm}$, respectively (CineScan 'S'; Quantel Medical, Bozeman, Mont., USA). No other findings apart from moderate nuclear lens opacity in both eyes were found in the anterior segment. Fundus examination revealed myopic changes, including posterior staphyloma and mild chorioretinal atrophy around the optic disc. After the complete ophthalmological examination, no other cause but the corneal ectasia could be found to explain the severe vision loss.

Pachymetric maps, using the Pentacam, a Scheimpflug-based imaging system (Oculus Optikgeräte $\mathrm{GmbH}$, Wetzlar, Germany), revealed a central pachymetry of $720 \mu \mathrm{m}$ in the right and of $710 \mu \mathrm{m}$ in the left eye, as well as an average paracentral pachymetry of 436 and $270 \mu \mathrm{m}$ in the 9 -mm zone, respectively. The thinnest areas on the temporal side were $290 \mu \mathrm{m}$ in the right eye and $81 \mu \mathrm{m}$ in the left eye. These findings were confirmed by ultrasonic corneal pachymetry (Corneo-Gage ${ }^{\mathrm{TM}}$ Plus; Sonogage Inc., Cleveland, Ohio, USA). Corneal topography (EyeMap version 6.2; CSO, Firenze, Italy) revealed irregular and asymmetric bowing in both eyes. In addition, generalized bilateral steepening was observed with high corneal power (fig. 3 ). The patient underwent a second larger bilateral PK - $9 \mathrm{~mm}$ this time - in an attempt to improve visual acuity. Six months after this second keratoplasty, BCVA was $20 / 100$ in both eyes.

\section{Discussion}

We present a case of a patient diagnosed with bilateral keratoconus and treated for this condition with a PK in both eyes. Thirty-four years later, he presented with decreased vision and bilateral keratectasia.

The initial diagnosis of bilateral keratoconus 34 years before is to be discussed. If we believe the diagnosis was right, late keratoconus recurrence on the corneal graft could be an explanation for the current situation. Increasing astigmatism should have been 
expected as a sign of late progression of the keratoconus in the host cornea [9], but only a high spherical refractive error was found, with no astigmatic shift. Moreover, pachymetry of the corneal button was not reduced $(715$ and $709 \mu \mathrm{m})$, with no central thinning as would be expected in a keratoconus recurrence. Corneal thinning was observed outside the graft (436 and $270 \mu \mathrm{m}$ in the $9-\mathrm{mm}$ zone). Thus, if the patient did not have a recurrence but a keratoconus, the actual corneal profile could also be secondary to a severe PK wound thinning, developing many years after a graft. Nevertheless, the thinning usually observed in this situation is not so severe and not for $360^{\circ}$.

However, a misdiagnosed previous keratoglobus with a secondary keratectasia generated by a peripheral thinning of the cornea could also be a possible explanation for the actual corneal ectasia, which is more plausible for us. The diameter of the transplant would have been sufficient for a keratoconus, but was not large enough to stabilize the graft-host junction in a keratoglobus. The small-diameter PK significantly improved the patient's visual acuity, probably secondary to the flattening effect of the graft rather than to the resolution of his underlying condition. The mechanism of production of this globular corneal contour is not totally clear, but wound weakness in the area of the grafthost junction could be a possible cause. This idea was already stated by Cameron [1], who reported a case of limbus-to-limbus thinning and globular contour in a patient who underwent two PK in the same eye. He suggested that in most cases of keratoglobus, the marked mid-peripheral thinning could represent the relative weakness of this area and be the main predisposing factor for developing such a contour. In the patient described by Cameron, though, the thinning involved both the central and peripheral cornea and the IOP was $40 \mathrm{~mm} \mathrm{Hg}$, which could have contributed to the global ectasia. In our case, the IOP was normal and the mechanical stress of the grafts was not especially high.

In summary, we present a case with an end-stage evolution of a corneal ectasia and severe bilateral visual impairment, many years after a PK in both eyes. Whether this situation was originally caused by a keratoconus or by a misdiagnosed keratoglobus with secondary keratectasia cannot be cleared at the present time. Nevertheless, this new condition was satisfactorily treated with larger PK in both eyes. 


\begin{tabular}{|c|c|c|c|}
\hline $\begin{array}{l}\text { Case Reports in } \\
\text { Ophutalmology }\end{array}$ & $\begin{array}{l}\text { Case Rep 0phthalmol 2010;1:24-29 } \\
\text { D0I: 10.1159/000316919 }\end{array}$ & Published online: July 2, 2010 & \begin{tabular}{|l} 
@ 2010 S. Karger AG, Basel \\
ISSN 1663-2699 \\
www.karger.com/cop
\end{tabular} \\
\hline
\end{tabular}

Fig. 1. Slit-lamp photograph showing clear corneal button in the right eye, taken when the patient was admitted with complaints of decreased visual acuity.

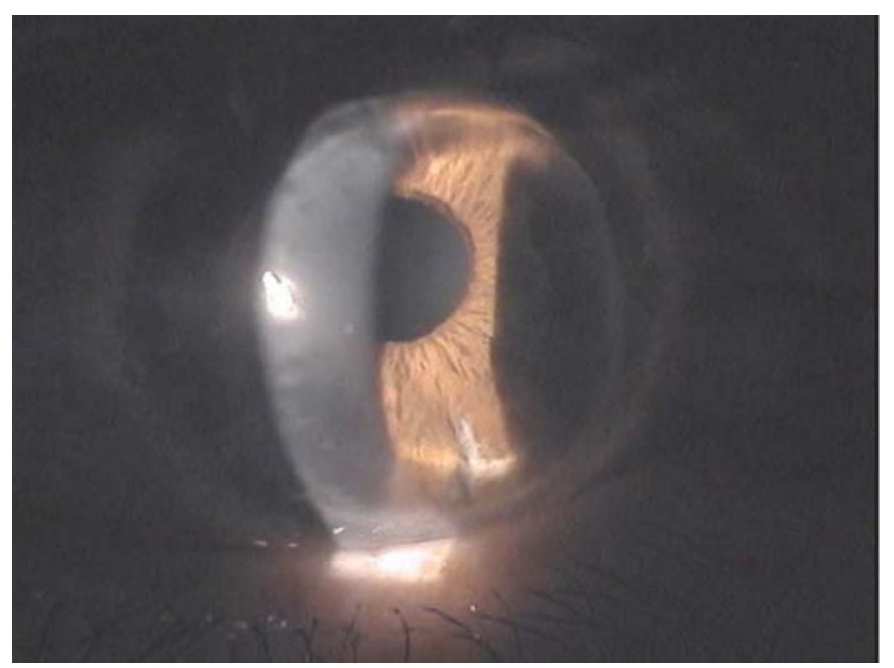

Fig. 2. Picture showing the left (a) and right (b) eye cornea profile with severe corneal ectasia. Vertical and horizontal diameters were 11.0 and $11.6 \mathrm{~mm}$ in the right eye, and 11.0 and $11.8 \mathrm{~mm}$ in the left eye, respectively.

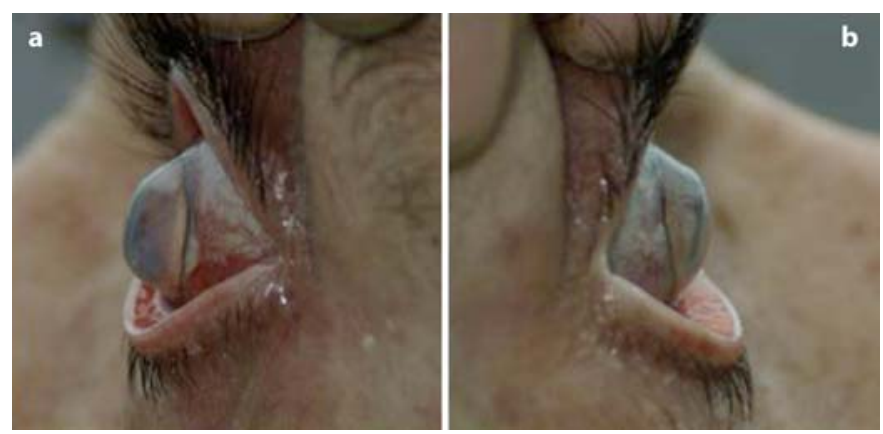




\begin{tabular}{|c|c|c|c|}
\hline $\begin{array}{l}\text { Case Reports in } \\
\text { Ophutalmology }\end{array}$ & $\begin{array}{l}\text { Case Rep 0phthalmol 2010;1:24-29 } \\
\text { D0I: 10.1159/000316919 }\end{array}$ & Published online: July 2, 2010 & \begin{tabular}{|l} 
@ 2010 S. Karger AG, Basel \\
ISSN 1663-2699 \\
www.karger.com/cop
\end{tabular} \\
\hline
\end{tabular}

Fig. 3. Pentacam anterior corneal curvature map for the right eye (a) and the left eye (b), revealing irregular bowing with generalized steepening and high corneal power.

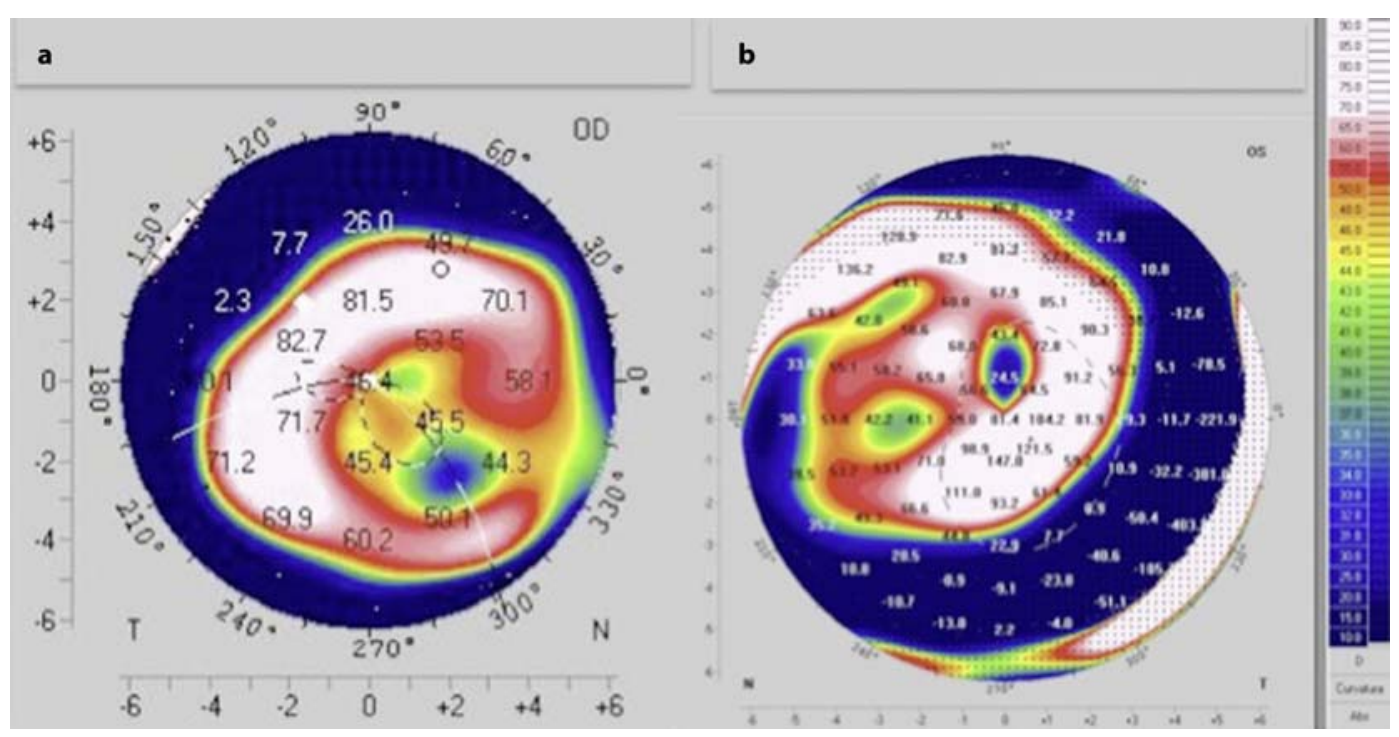




\begin{tabular}{l|l|l|l}
$\begin{array}{l}\text { Case Reports in } \\
\text { CPithalmology }\end{array}$ & $\begin{array}{l}\text { Case Rep 0phthalmol 2010;1:24-29 } \\
\text { D0I: 10.1159/000316919 }\end{array}$ & Published online: July 2, 2010 & $\begin{array}{l}\text { 2010 S. Karger AG, Basel } \\
\text { ISSN 1663-2699 } \\
\text { www.karger.com/cop }\end{array}$ \\
\hline
\end{tabular}

\section{References}

1 Cameron JA: Keratoglobus. Cornea 1993;12:124-130.

-2 Pouliquen Y, Dhermy P, Espinasse MA, Savoldelli M: Keratoglobe. J Fr Ophthalmol 1985;8:43-54.

3 Biglan AW, Brown SI, Johnson BL: Keratoglobus and blue sclera. Am J Ophthalmol 1977;83:225-233.

4 Elder MJ: Leber congenital amaurosis and its association with keratoconus and keratoglobus. J Pediatr Ophthalmol Strabismus 1994;31:38-40.

5 Karabatsas CH, Cook SD: Topographic analysis in pellucid marginal corneal degeneration and keratoglobus. Eye 1996;10:451-455.

-6 Javadi MA, Kanavi MR, Ahmadi M, Yazdani S: Outcomes of epikeratoplasty for advanced keratoglobus. Cornea 2007;26:154-157.

7 Jacobs DS, Green WR, Maumenne AE: Acquired keratoglobus. Am J Ophthalmol 1974;77:393-399.

8 Kanellopoulos AJ, Pe LH: An alternative surgical procedure for the management of keratoglobus. Cornea 2005;24:1024-1026.

$\checkmark 9$ de Toledo JA, de la Paz MF, Barraquer RI, Barraquer J: Long-term progression of astigmatism after penetrating keratoplasty for keratoconus: evidence of late recurrence. Cornea 2003;22:317-323. 